\title{
Effects of particle shape and size on nanofluid properties for potential Enhanced Oil Recovery (EOR)
}

\author{
Tengku Amran Tengku Mohd ${ }^{1,2}$, Jumadi Baco ${ }^{1}$, Noor Fitrah Abu Bakar ${ }^{1}$ and Mohd Zaidi Jaafar ${ }^{2}$ \\ ${ }^{1}$ Faculty of Chemical Engineering, Universiti Teknologi MARA, Shah Alam, MALAYSIA \\ ${ }^{2}$ Faculty of Chemical and Energy Engineering, Universiti Teknologi Malaysia, Skudai, MALAYSIA
}

\begin{abstract}
Application of Enhanced Oil Recovery (EOR) in oil and gas industry is very important to increase oil recovery and prolong the lifetime of a reservoir but it has been very costly and losing properties of EOR agent due to harsh condition. Nanoparticles have been used in EOR application since they are not degradable in reservoir condition and used in smaller amount compared to polymer usage. Commonly, EOR techniques are focusing on increasing the sweep efficiency by controlling the mobility ratio between reservoir fluid and injected fluid. Thus, this research aimed to analyze the nanofluid viscosity at different particle size and shape, volumetric concentration and types of dispersing fluid, as well as to determine the oil recovery performance at different nanofluid concentration. The nanofluid viscosity was investigated at nanoparticle sizes of $15 \mathrm{~nm}$ and $60 \mathrm{~nm}$ and shapes of $15 \mathrm{~nm}$ spherical-solid and porous. Five nanofluid samples with concentration ranging from $0.1 \mathrm{wt} . \%$ to $7 \mathrm{wt} . \%$ were used to investigate the effect of volumetric concentration. Distilled water, ethanol, ethylene glycol (EG) and brine were used for the effect of dispersing fluids. Oil recovery was investigated at five different concentrations of nanofluid samples through flooding test. It was found that viscosity of nanofluid increased with decreasing particle size and increasing volumetric concentration. Solid shape particle and increasing dispersing fluid viscosity resulted in higher nanofluid viscosity. The higher the nanofluid concentration, the higher the oil recovery obtained. It can be concluded that nanofluid properties have been significantly affected by the environment and the particle used for potential EOR application.
\end{abstract}

\section{Introduction}

Enhanced Oil Recovery (EOR) has become the best solution to solve the problem of declining production and to prolong the life of a reservoir. By using this technique, the recovery performance for a reservoir can be increased up to $60 \%$ of oil compared to the conventional method which can only recover between $20-40 \%$ of oil [1]. EOR comes with several methods such as injection of miscible solvents and liquid carbon dioxide $\left(\mathrm{CO}_{2}\right)$ superfluid, polymer flooding, surfactant flooding, microbial injection and thermal methods. Besides that, another interesting method used is injection of nanofluids [2].

Nanofluid is a mixture of nano-sized solid particles; usually less than $100 \mu \mathrm{m}$ and its base liquid as shown in Fig. 1. Examples of nanoparticles are metal oxides such as $\mathrm{SiO}_{2}, \mathrm{CuO}, \mathrm{Al}_{2} \mathrm{O}_{3}, \mathrm{MgO}$ and etc. while for the base fluids are water, brine, ethylene glycol, and etc. Nanofluid can be prepared in several ways such as singlestep method and two-step method. One-step method is a process where preparation of nanoparticles and synthesis of nanofluids are done in a two-combined process while two-step method involves synthesizing of nanoparticles first and then mixing with base fluids [3].

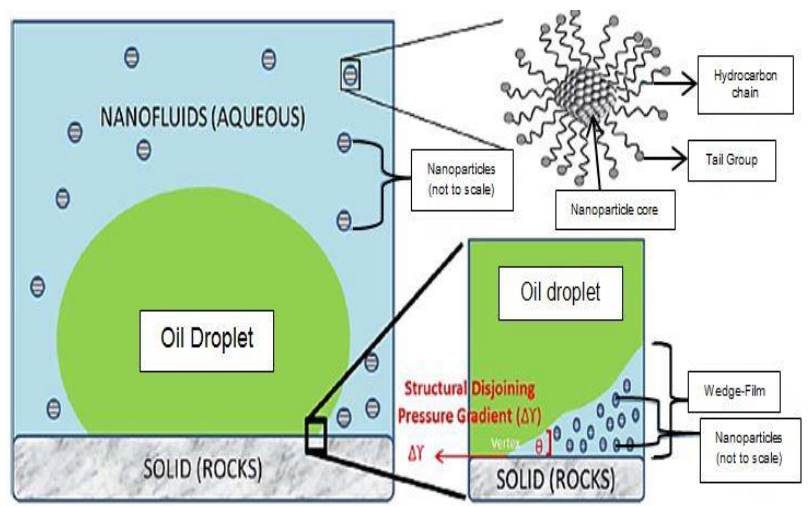

Figure 1. Structure of nanoparticle [3].

For oil and gas industry, one of the mechanisms of nanofluids that can be used for EOR method is viscosity alteration which is very important especially in recovering heavy oil. In addition, it can also be used to control the viscosity of displacing fluid (nanofluid) which then improves the mobility ratio thus increase the oil recovery. Sweep efficiency is influenced by mobility ratio (M) which is also dependent on the mobility of displacing fluid and displaced fluid (oil). The key of controlling the mobility ratio is by altering the viscosity of each one or both of the fluids [4]. This can be expressed in Equation 1. 


$$
M=\frac{\lambda_{A}}{\lambda_{B}}
$$

where; $\lambda=$ mobility $=\mathrm{k} / \mu, \mathrm{k}=$ permeability, $\mu=$ viscosity, $\mathrm{A}=$ displacing fluid and $\mathrm{B}=$ displaced fluid. The favorable value for mobility ratio is below than 1 while larger than that indicate low sweep efficiency [5]. The effect of mobility ratio is illustrated in Fig. 2. Basically, low mobility ratio is favorable to displace a fluid whereas high mobility ratio will reduce the sweep efficiency due to the "fingering effect" problem. In the industry, polymers are known to have the ability to increase the viscosity of a fluid but very costly compared to nanoparticles which required only in small amount due to its large surface area [6].

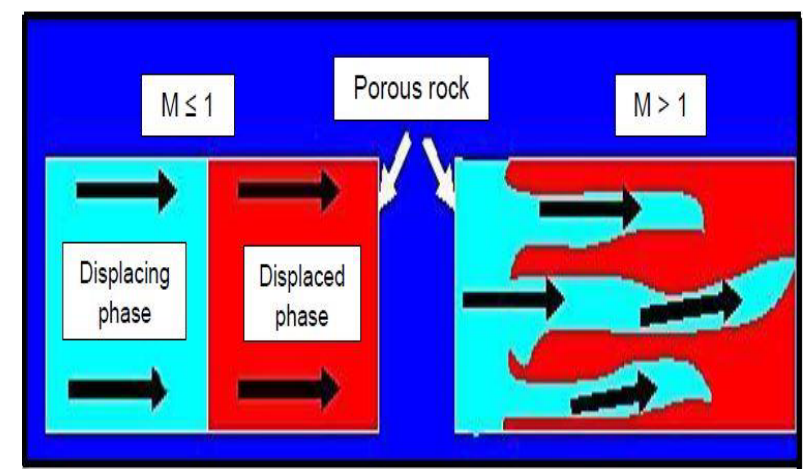

Figure 2. Mobility ratio effect on sweep efficiency [7].

Nanoparticles have been developed for various applications in EOR and can be summarized in three approaches, which are nanocatalysts, nanoemulsions and nanofluids [8]. The presence of nano-sized metal particles catalyzes the breaking of carbon-sulfur bonds within asphaltenes [9]. High viscosity provided by nanoparticlestabilized emulsions can improve mobility ratio during the flooding, thus increase oil recovery. Mohd et al. (2015) have investigated the mobility of nanoparticlestabilized $\mathrm{CO}_{2}$ foam, who found reduction of mobility resulting in enhancing oil recovery [10]. Foam stability also increased with increasing nanoparticle concentration [11]. Zirconium oxide based nanofluids have been applied for wettability alteration, which have great potentials in changing oil-wet limestone towards strongly water-wet condition [12].

Several studies have been done to investigate the particle size effect on the viscosity of a nanofluid. Nguyen et al. (2007) found that the viscosity of nanofluid increased with increasing particle size in their studies on $\mathrm{Al}_{2} \mathrm{O}_{3}$-water nanofluid [13]. However, several contradictory results have also been obtained. A study by $\mathrm{Lu}$ and Fan (2008) on $\mathrm{Al}_{2} \mathrm{O}_{3}$-water and ethylene glycol (EG) for different nanoparticle sizes showed the decrease in viscosity with increasing particle size [14]. Another study using $\mathrm{SiO}_{2}$ nanoparticles with sizes of 20,50, $100 \mathrm{~nm}$ also found that viscosity reduced with the increase of particle size [15]. There was limited research investigating the effect of particle shape on nanofluid viscosity. However, some studies found that the viscosity of nanofluid was greatly dependent on the particle shape.
Timofeeva et al. (2011) reported that elongate particles like platelets and cylinders resulted in higher viscosity compared to spherical particles at the same volume fraction. Other shapes of nanoparticles are spherical, rod, sheet, etc. [16]. Based on previous researches, there was no contradiction about the effect of volumetric concentration on nanofluid viscosity. Das et al. and Putra et al. in 2003 proved that viscosity of nanofluid increased with increasing particle concentration $[17,18]$. Thus, this paper aims to analyze the nanofluid viscosity with respect to nanoparticle shape and size, volumetric concentration and types of dispersing fluids, as well as investigating oil recovery at different volumetric concentration.

\section{Methodology}

Two major experiments have been conducted at room temperature and atmospheric pressure in order to meet the objectives of this research. The first part was the investigation of nanofluid properties and followed by oil recovery flooding test.

\subsection{Preparation of nanofluid samples}

The main materials used in this research were silicon dioxide $\left(\mathrm{SiO}_{2}\right)$ nanoparticles (spherical-solid shape of 15 and $60 \mathrm{~nm}$ as well as porous shape nanoparticle) purchased from US Research Nanomaterials Incorporation. These materials were used as they have been received. Paraffin oil, which was used to represent the real oil inside the sand pack for flooding test and Alpha-olefin Sulfonate (AOS) surfactant were provided by Chem Laboratory. Basically, the preparation of nanofluid for this research used two-step method, whereby nanofluids have been formed by dispersing solid nanoparticles into base fluid. Although aggregation of particles was the main challenge for this method, the problem has been minimized by adding some surfactant and application of ultrasonic. Viscosity tests were carried out using Brookfield DV-II+ Viscometer due to its suitability to measure the nanofluid viscosity. Ten readings were taken for every 30 seconds and the average of viscosity was calculated.

\subsubsection{Effect of particle size}

The nanofluid samples were prepared using $\mathrm{SiO}_{2}$ nanoparticle. Two different sizes of $\mathrm{SiO}_{2}$ nanoparticle used were $15 \mathrm{~nm}$ and $60 \mathrm{~nm}$; dispersed in distilled water at concentration of $5 \mathrm{wt} . \%$. To increase the nanofluids stability, 0.1 wt.\% of surfactant was added and then sonicated for 15 minutes.

\subsubsection{Effect of particle shape}

The nanofluid samples were prepared using two different shapes of $\mathrm{SiO}_{2}$ nanoparticle; spherical-solid shape and porous shape. Both samples were dispersed in distilled water at $5 \mathrm{wt} . \%$ concentration. $0.1 \mathrm{wt} . \%$ of surfactant was added and then sonicated for 15 minutes to increase the samples stability. 


\subsubsection{Effect of volumetric concentration}

$\mathrm{SiO}_{2}$ nanoparticle was dispersed in distilled water. Five samples of nanofluids were prepared with concentration of 0.1 wt. $\%, 0.5$ wt. $\%, 2$ wt. $\%, 5$ wt. $\%$ and 7 wt. $\%$. To retain fluid stability, $0.1 \mathrm{wt} . \%$ surfactant was added into each sample and then sonicated for 15 minutes.

\subsubsection{Effect of types of dispersing fluid}

Four samples of nanofluids were prepared using $\mathrm{SiO}_{2}$ nanoparticles at concentration of $5 \mathrm{wt} . \%$. Distilled water (DI), ethanol, ethylene glycol (EG) and also brine solution (30000ppm) were used as dispersing fluids with $0.1 \mathrm{wt} . \%$ surfactant and then sonicated for 15 minutes to prevent aggregation of particles.

\subsection{Oil recovery flooding test}

The flooding test was carried out to study the mechanism of nanofluid to recover oil in porous media. Sand pack was used as the porous media while paraffin oil to substitute crude oil. Paraffin oil was coloured with red dye to differentiate it with brine. The volume of oil recovered was divided to the total volume of oil inside the sand pack to measure the percentage of oil recovery. The oil recovery flooding test setup is shown in Fig. 3.

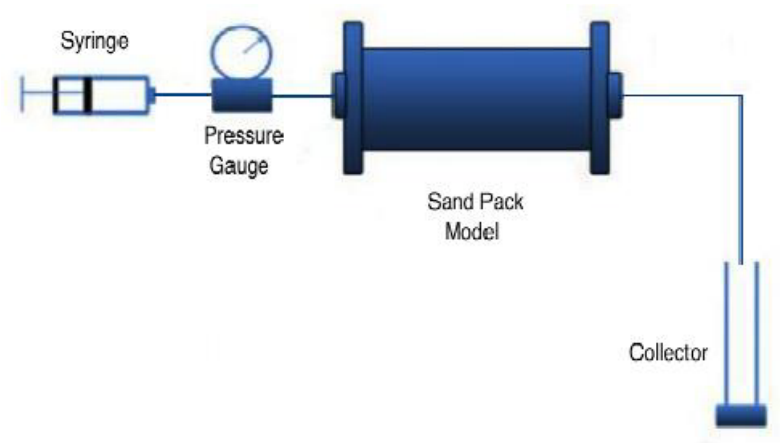

Figure 3. Flooding Test setup.

Sand pack was prepared using sieve shaker to get the uniform size of sand grain between 150-300 microns. The meshed sand was filled into the sand pack holder fully and tightly. The flooding setup includes the main components of sand pack, syringe pump, pressure gauge and measuring cylinder (collector). Firstly, the sand pack was fully injected with brine. Then, paraffin oil was injected into the sand pack until no water can be displaced anymore or called as irreducible water saturation. After that, the secondary recovery was applied to the system using brine which was injected at constant rate of $4 \mathrm{ml} / \mathrm{min}$ to recover the oil inside the sand pack. The oil recovered was collected in measuring cylinder and then calculated. Nanofluid was then injected into the sand pack to determine the recovery of EOR. For this purpose, different concentrations of nanofluids were injected at 0.1 wt. $\%, 0.5$ wt. $\%, 3$ wt. $\%, 5$ wt. $\%$ and 7 wt.\%. The injection was kept at constant rate of $4 \mathrm{ml} / \mathrm{min}$ and the collected oil recovery in the measuring cylinder was calculated.

\section{Results and discussion}

\subsection{Investigation of nanofluid viscosity}

\subsubsection{Effect of particle size}

Fig. 4 shows the result of nanofluid viscosity versus particle size where the viscosity decreased as the particle size increased.

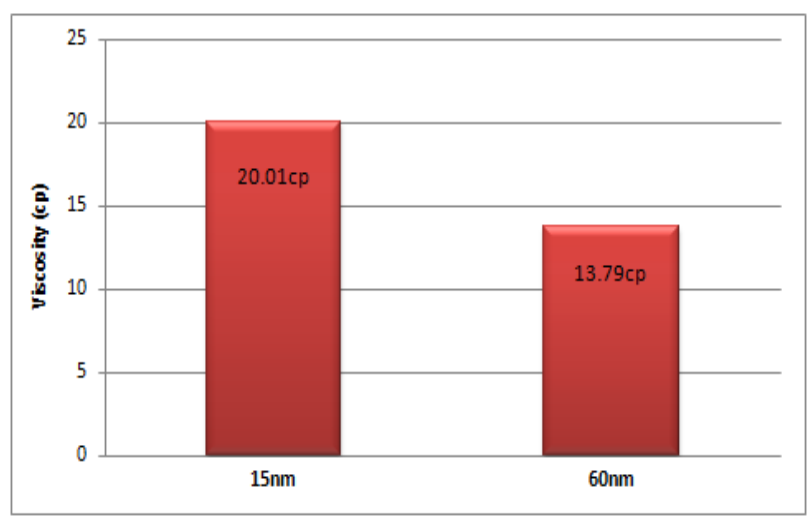

Figure 4. Viscosity versus particle size.

This was supported by finding from Chevalier et al. (2007), who measured the viscosity of $\mathrm{SiO}_{2}$-ethanol for three different sizes of particle diameter 35, 94 and 190 $\mathrm{nm}$ [19]. Similar result was also found by $\mathrm{Lu}$ and Fan (2008) and Pastoriza-Gallego et al. (2011), who investigated the viscosity of $\mathrm{CuO}$-water with sizes ranging 23-37nm [14]. According to Bryn McDonagh (2011), in a constant volume fraction, the number of particles increased when particle size decreased resulting in increasing interactions between particles, which then leading to an overall increase resistance to flow [20].

\subsubsection{Effect of particle shape}

Fig. 5 illustrates nanofluid viscosity versus particle shape, whereby spherical-solid shape provided higher nanofluid viscosity than the sample with porous shape.

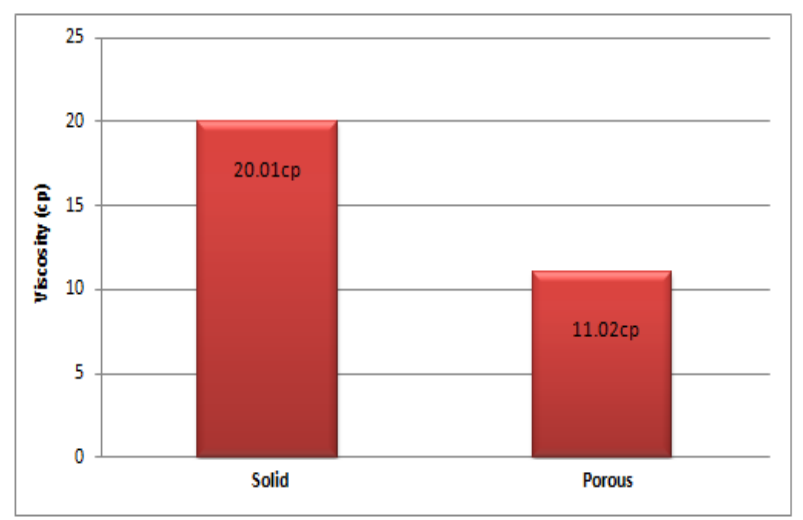

Figure 5. Viscosity versus particle shape.

According to Timofeeva et al. (2009), elongate particle such as platlets and cylinders resulted in high nanofluid viscosity compared to spherical shape [16]. As 
porosity reduced the resistance of fluid to flow during in contact with surface, hence the viscosity was reduced too $[21,22]$. Based on this statement, it can be concluded that the result was acceptable as the viscosity for sample with porous shape was lower than the sample with sphericalsolid shape. Although there were not many researches focusing on particle shape, this parameter can be a strong factor in manipulating the viscosity of nanofluid to suit the requirement of its application.

\subsubsection{Effect of volumetric concentration}

From Fig. 6, it can be clearly seen that the viscosity of nanofluid increased as the volumetric concentration increased. In lower concentration, low amount of particles were inside the water, thus less resistance for the fluid to flow resulting the flow property of water to be dominating. In contrast, for higher concentration solution, there were higher amount of particles, which resulted in more resistance as the particles collided each other and reducing the original flow property of the water; higher viscosity [23]. This result was supported by several researchers, who found identical results. For example, Das et al. (2008) reported that increasing $\mathrm{Al}_{2} \mathrm{O}_{3}$-water nanofluid concentration has resulted in increasing nanofluid viscosity [24]. Nguyen et al. (2007) concluded that particle size effects are more significant for high particle volume percentage. Their studies on $\mathrm{Al}_{2} \mathrm{O}_{3}$-water nanofluid exhibited that for volume concentrations below $4 \%$, viscosities corresponding to $36 \mathrm{~nm}$ and $47 \mathrm{~nm}$ particle size were almost equal. In contrast, for higher concentrations, viscosities were very different [13].

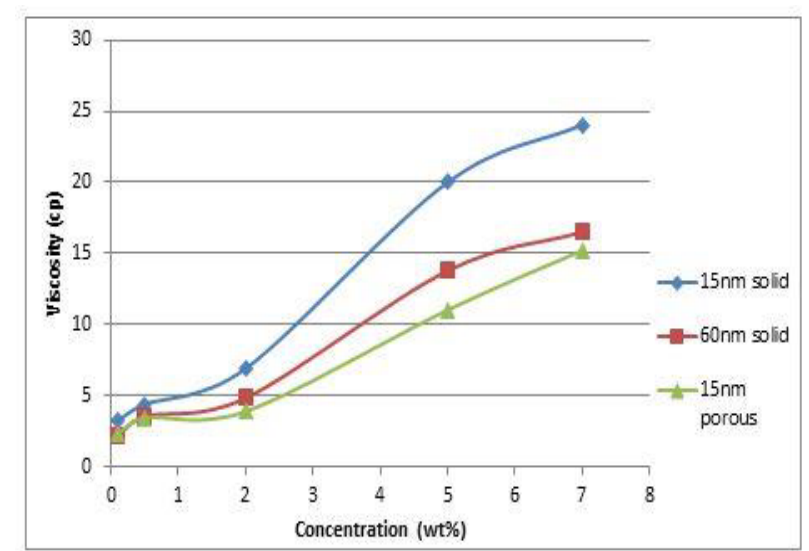

Figure 6. Viscosity versus volumetric concentration.

\subsubsection{Effect of dispersing fluid type}

Fig. 7 shows the average viscosity of nanofluid samples dispersed in four different fluids. The average viscosities were found to be $20 \mathrm{cp}, 36.3 \mathrm{cp}, 19.52 \mathrm{cp}$ and $20.43 \mathrm{cp}$ for the samples using DI, EG, ethanol and brine, respectively. The highest viscosity was achieved by using EG as the dispersing fluid while the lowest was when using water. These results were affected by the viscosity of the dispersing fluid itself as the viscosity of EG and ethanol were approximately $20 \mathrm{cp}$ and $1 \mathrm{cp}$, respectively at room temperature. Thus, it can be concluded that the viscosity of nanofluid was dependent on the viscosity of its dispersing fluid.

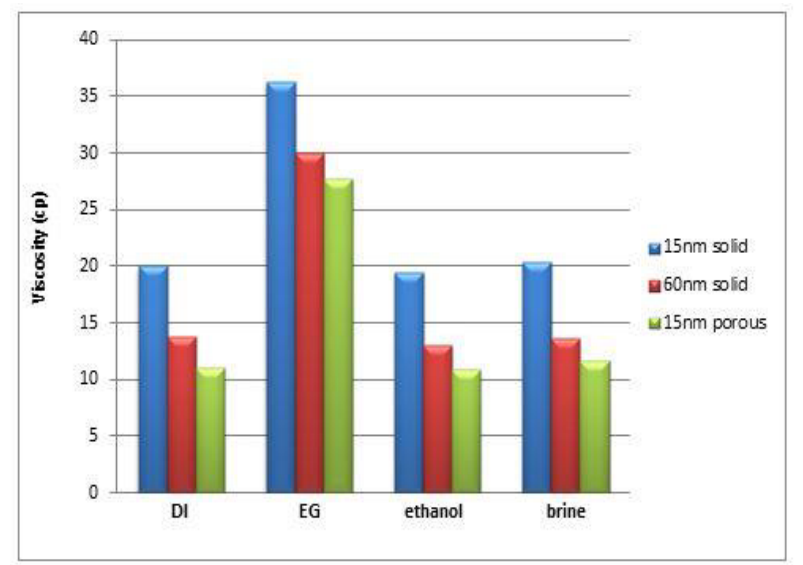

Figure 7. Viscosity versus type of dispersing fluid.

The average viscosity for samples using DI and brine were almost the same to the sample using water as the original viscosities for the three dispersing fluid were nearly the same. The investigation of nanofluid viscosity with respect to different dispersing fluid is important as the property of dispersing fluid could be one of the factors to influence the nanofluid produced. Besides that, further studies of dispersing fluid could be beneficial to enhance the application of nanofluid. Selection of dispersion fluid used was based on several researches such as in a study of $\mathrm{Al}_{2} \mathrm{O}_{3}$-water and ethylene glycol (EG) for different volume fractions and in a study of SiO2-ethanol with three different nanoparticle sizes [19, $14]$.

\subsection{Investigation of oil recovery}

Fig. 8 shows the result of oil recovery based on varying nanofluid concentration. From the figure, the oil recovery increased as the concentration of nanofluid increased.

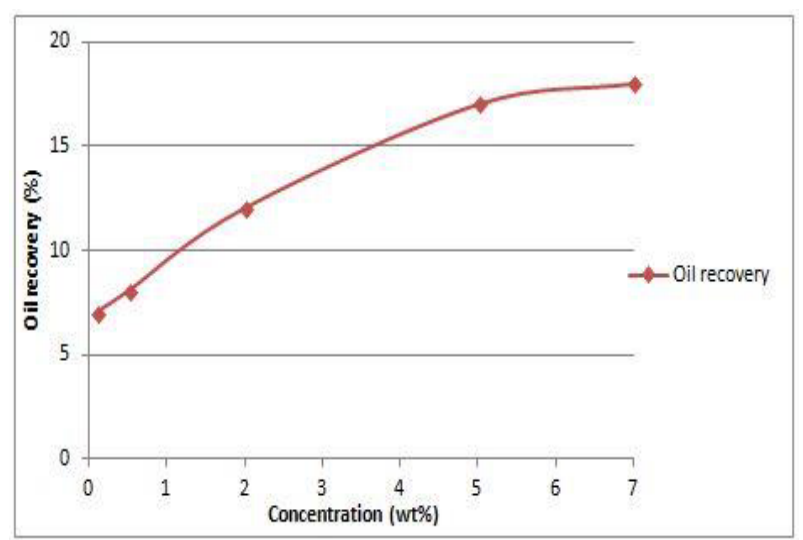

Figure 8. Oil recovery versus nanofluid concentration.

The lowest oil recovery was obtained from the injection of $0.1 \mathrm{wt} . \%$ of nanofluid with percentage of $7 \%$ recovery while the highest recovery was from the injection of 7 wt.\% of nanofluid with $18 \%$ recovery. However, the injection of $7 \mathrm{wt} \%$ of nanofluid might contribute to some problems due to higher precipitation 
of nanoparticle. According to Hendraningrat et al. (2013), high nanoparticle concentration and injection rate could lead to high impairment. The retention of nanoparticles inside the core plugs induced porosity and permeability with some blockage to reservoir hence reduced the porosity [25].

From this experiment, small difference of oil recovery (1\%) was found between $7 \mathrm{wt} . \%$ and $5 \mathrm{wt} . \%$ of nanofluid. Furthermore, the precipitation rate for $5 \mathrm{wt} . \%$ sample was low, indicating small effect on the reservoir porosity. By this consideration, it can be concluded that $5 \mathrm{wt} \%$ nanofluid was the most effective concentration to be used in recovering oil as it could provide high oil recovery, low precipitation rate and less impact to the reservoir properties. For this flooding test, only $\mathrm{SiO}_{2}$ nanoparticle with size of $15 \mathrm{~nm}$ and spherical-solid in shape was chosen in preparing the nanofluid samples. The selection was based on previous viscosity tests, which resulted in highest viscosity and DI as the dispersing fluid by considering the economic benefit for industrial application.

This result also proved the Equation 1 which theoretically explained that high viscosity of displacing fluid reduced the mobility of that fluid, resulting in mobility ratio less than one [4]. Fig. 8 shows the highest percentage of oil recovered was from the highest concentration of nanofluid sample, and vice versa. This was due to 7 wt.\% nanofluid concentration had the highest viscosity which could recover the paraffin oil inside the sand pack more effectively. Maintaining low mobility ratio is very important to increase the sweep efficiency for recovering more oil and minimizing 'fingering effect' $[5,7]$.

\section{Conclusion}

The present study has revealed that the application of EOR can help to increase the total oil recovery and prolong the life of reservoir. From this experiment, it can be concluded that viscosity of nanofluid increased as the particle size decreased, volumetric concentration increased, using of solid shape particle instead of porous shape and also using high viscosity of dispersing fluid. From the flooding test, the percentage of oil recovery increased with increasing concentration of injected fluid but too high concentration could damage the reservoir productivity. The outcomes could be very useful for industrial application as it provides new knowledge on nanofluid properties with respect to particle shape and size, volumetric concentration and types of dispersing fluids to fully optimize the potential of nanofluid properties. This could be potentially applied in nanofluid flooding of EOR application.

\section{Acknowledgment}

The authors would like to thank the Faculty of Chemical Engineering, UiTM Shah Alam for the facilities and constant encouragement. This work was financially supported by the Fundamental Research Grant Scheme (FRGS): 600-RMI/FRGS 5/3 (28/2013).

\section{References}

1. A. Amarnath, "Enhanced oil recovery scoping study," (1999).

2. J.J Taber, F.D. Martin, and R.S Seright, "EOR screening criteria revisited," Paper presented at the Symposium on improved oil recovery (1996).

3. H.T Zhu, Y.S Lin, and Y.S Yin, "A novel one-step chemical method for preparation of copper nanofluids," Journal of Colloid and Interface Science, 277(1), 100-103 (2004).

4. J.G Richardson, and H.L Stone, "A quarter century of progress in the application of reservoir engineering," Journal of Petroleum Technology, 25(12), 1371-1379 (1973).

5. T.D. Ma, and G.K Youngren, "Performance of immiscible water-alternating-gas (IWAG) injection at Kuparuk River Unit, North Slope, Alaska," Paper presented at the SPE Annual Technical Conference and Exhibition (1994).

6. N. Kothari, B. Raina, K. Chandak, V. Iyer, and H. Mahajan, "Application of ferrofluids for enhanced surfactant flooding in IOR," Paper presented at the SPE EUROPEC/EAGE Annual Conference and Exhibition (2010).

7. R.S. Seright, 'Clean Up of Oil Zones after a Gel Treatment," Paper presented at the SPE International Symposium on Oilfield Chemistry (2005).

8. R. A. F. Elsayed. "A Comparative Study between nanoparticles Method and the Other Methods for Increasing Heavy Oil Recovery", MSc. thesis, Suez University (2014).

9. Y. H. Shokrlu and T. Babadagli: "Transportation and Interaction of Nano and Micro Size Metal Particles Injected to Improve Thermal Recovery of HeavyOil”, SPE 146661-PA, DOI: 10.2118/146661-PA (2013).

10. T. A. T. Mohd, N. Alias, N. A. Ghazali, E. Yahya, A. Sauki, A. Azizi, \& N. M. Yusof. "Mobility Investigation of Nanoparticle-Stabilized Carbon Dioxide Foam for Enhanced Oil Recovery (EOR)". Advanced Materials Research, 1119, 90-95 (2015).

11. T. A. T. Mohd, A. H. M. Muhayyidin, N. A. Ghazali, M. Z. Shahruddin, N. Alias, S. Arina and N. A. Ramlee. "Carbon Dioxide $\left(\mathrm{CO}_{2}\right)$ Foam Stability Dependence on Nanoparticle Concentration for Enhanced Oil Recovery (EOR)". Applied Mechanics and Materials, 548-549, 1876-1880 (2014).

12. L. N. Nwidee, S. Al-anssari, A. Barifcani, M. Sarmadivaleh \& S. Iglauer. "Nanofluids for Enhanced Oil Recovery Processes : Wettability Alteration Experimental Set-Up". Paper presented at the Offshore Technology Conference Asia, Kuala Lumpur, Malaysia, 22-25 March 2016 (2016).

13. C. Nguyen, F. Desgranges, G. Roy, N. Galanis, T. Mare, S. Boucher and H. Anguemintsa, "Temperature and particle-size dependent viscosity data for water-based nanofluids-hysteresis phenomenon," Int. J. Heat Fluid Flow 28 (6) 1492 1506 (2007).

14. W. Lu and Q. Fan, "Study for the particle's scale effect on some thermophysical properties of 
nanofluids by a simplified molecular dynamics method," Eng. Anal. Boundary Elem. 32 (4) 282289 (2008).

15. P.K. Namburu, D.P. Kulkarni, A. Dandekar and D.K. Das, "Experimental investigation of viscosity and specific heat of silicon dioxide nanofluids," Micro Nano Lett. 2 (3) 67-71 (2007).

16. E.V. Timofeeva, W. Yu, D.M. France, D. Singh and J.L. Routbort, "Nanofluids for heat transfer: an engineering approach," Nanoscale Res. Lett. 6 (1) 182 (2011).

17. S.K. Das, N. Putra and W. Roetzel, "Pool boiling characteristics of nano-fluids," Int. J. Heat Mass Transfer 46 (5) 851-86 (2003).

18. N. Putra, W. Roetzel and S.K. Das, "Natural convection of nano-fluids," Heat Mass Transfer 39 (8) 775-784 (2008).

19. J. Chevalier, O. Tillement and F. Ayela, "Rheological properties of nanofluids flowing through microchannels," Appl. Phys. Lett. 91 (23) 233103 (2007).
20. B. Mcdonagh, "Wiley-Blackwell discount." Universal, Fortuna (2011).

21. R. E. Larson, and J. J. L. Higdon. "Microscopic flow near the surface of two-dimensional porous media. Part 1. Axial flow." Journal of Fluid Mechanics 166: 449-472 (1986).

22. L. Hendraningrat, B. Engeset, S. Suwarno, S. Li and O. Torsæter, "Laboratory investigation of porosity and permeability impairment in Berea sandstones due to hydrophilic nanoparticle retention", Paper SCA2013-062, California, USA (2013).

23. N. Putra, W. Roetzel and S.K. Das, "Natural convection of nano-fluids," Heat Mass Transfer 39 (8)775-784 (2008).

24. S.K Das, S.U. Choi, W. Yu, and T. Pradeep, "Nanofluids: science and technology," WileyInterscience Hoboken, NJ (2008).

25. L. Shidong, L. Hendraningrat, and O. Torsaeter. "Improved Oil Recovery by Hydrophilic Silica Nanoparticles Suspension: 2 Phase Flow Experimental Studies." IPTC 2013: International Petroleum Technology Conference (2013). 